\title{
Otolith biochronology reveals factors underlying dynamics in marine fish larvae
}

\author{
Kung-Sik Chan ${ }^{1, *}$, Tianyang Zhang ${ }^{1}$, Kevin M. Bailey ${ }^{2}$ \\ ${ }^{1}$ Department of Statistics and Actuarial Science, University of Iowa, 263 Schaeffer Hall, Iowa City, Iowa 52242, USA \\ ${ }^{2}$ Alaska Fisheries Science Center, National Marine Fisheries Service, NOAA, 7600 Sand Point Way NE, Seattle, \\ Washington 98115, USA
}

\begin{abstract}
Study of the dynamics in marine fish larvae is notoriously difficult, given their minute size in a vast, complex and variable marine environment. We demonstrate a novel statistical approach, utilizing a panel of 19 annual hatchdate distributions, to unravel environmental and potential harvesting effects on the spawning, hatching and survival processes for walleye pollock in the Gulf of Alaska. Hatchdates are determined from counting daily increments on otoliths of larvae. The hatchdate frequency distribution determined from sampling a population of larvae depends on factors influencing birth and death processes, i.e. spawning times and survival rates. Using a nonlinear and partly parametric statistical model, temperature, strong winds, and the age frequency of spawning adults were found to strongly influence hatchdates. Moreover, the interaction of both a climate regime shift and the 'Exxon Valdez' oil spill in 1989 suppressed pollock larval abundance in 1989, with geometrically diminishing after-effects lasting until around 1992. The novel method presented here provides a general framework for unlocking the rich information hidden in hatchdate data about environmental and/or intervention effects on dynamics in marine fishes.
\end{abstract}

KEY WORDS: Environmental factors - Hatchdate distribution - Interventions · Partly parametric nonlinear regression - Walleye pollock - Recruitment

Resale or republication not permitted without written consent of the publisher

\section{INTRODUCTION}

Marine fish populations are generally subject to severe annual fluctuations due to multiple environmental interactions and their effects on spawning and survival processes (e.g. Cushing 1990, Fromentin et al. 2001, Houde 2008, Hsieh et al. 2009). Marine environ-

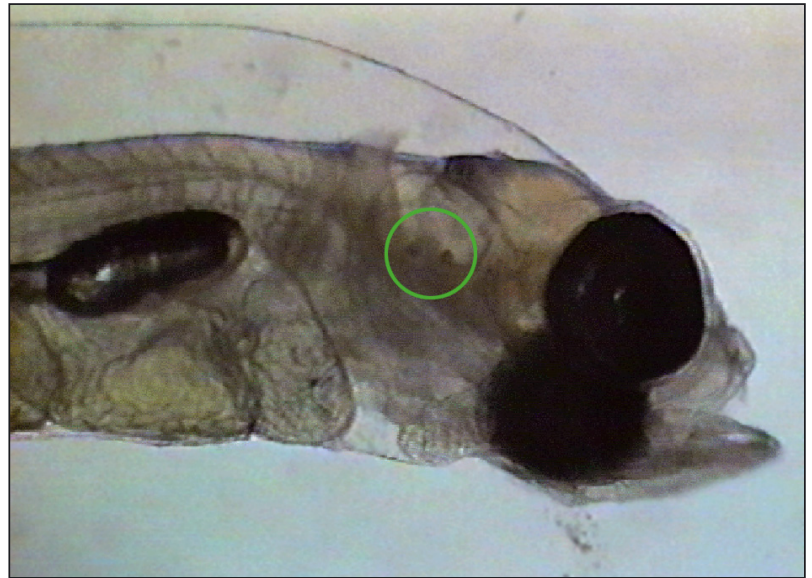

Head of a walleye pollock Theragra chalcogramma larva showing otoliths (small dark spots within green circle).

Photo: National Oceanic and Atmospheric Administration

mental conditions can be highly variable, with occasional drastic changes brought about by, for example, (climate) regime shifts, as well as natural and/or manmade interventions such as algal blooms or oil spills (Chan et al. 2003) - an intervention is a disruptive event, as opposed to an environmental gradient (Box \& Tiao 1975). Regime shifts and interventions, however, provide opportunities for assessing the resilience of fish populations to severe perturbations (Chan et al. 2003). Gaining quantitative understanding of environmental or intervention effects on larval fish survival is, moreover, important in stock forecasting with regard to harvesting versus environmental effects.

Key elements for understanding these effects can be found in historical records of patterns in birth(hatch)date distributions of fish larvae collected in fisheries monitoring surveys (Bailey \& Macklin 1994), but lack of 
suitable analytical methodologies has left this cache of information largely unexplored. The shape and height of the annual hatchdate frequency distribution may be dynamically altered by events influencing the processes of spawning, hatching, and larval survival, which form the basis for inference on how environmental conditions shape the early dynamics in larval fish. In this study, we demonstrate a general statistical framework for untangling various environmental and intervention effects on spawning and larval survival, using hatchdate data and partly parametric nonlinear regression. This innovation originates from the unique analysis of data on walleye pollock Theragra chalcogramma larvae caught in Shelikof Strait during annual ichthyoplankton surveys.

Walleye pollock is a gadid species that is widely distributed across the North Pacific Ocean; it currently supports the world's second largest fishery and is a key species of the Gulf of Alaska (GOA) and other ecosystems, both as prey and predator (Ciannelli et al. 2005). The GOA pollock population experienced a rapid increase in the 1970s and early 1980s, but has recently been near collapse, having reached about $22 \%$ of its estimated unfished biomass (Dorn et al. 2008). In the western GOA, pollock spawning is localized at specific spawning grounds during restricted periods. Most spawning occurs in a deep sea valley, Shelikof Strait (Fig. 1), during the first $2 \mathrm{wk}$ in April (Bacheler et al. 2009). Eggs take about 2 wk to hatch, and larvae drift in the Alaska Coastal Current, where they may be retained by eddies, transported onto the continental shelf, or swept offshore into the swift-flowing Alaskan Stream. Shelikof Strait is at the center of storm activity in the GOA, and experiences considerable year-toyear variability in environmental conditions (Stabeno et al. 2004). Larvae have been sampled in surveys commencing in late May to early June since 1981. Based on counts of daily growth increments on their otoliths, the ages of pollock larvae collected in the surveys have been determined and are used here to estimate the annual hatchdate frequency of the population.

The proposed methodology applied to $19 \mathrm{yr}$ of annual hatchdate abundance data enabled us to reveal hidden information about the environmental effects on larval dynamics, similar to using dendrochronology to analyze the role of events and climate in tree and forest dynamics (Abrams et al. 2000). Some intertwined intervention effects may have influenced pollock in the GOA in 1989 and 1990, as acoustic survey estimates of the Shelikof spawning population differed markedly from those of age-structured stock assessment analysis models in those years (Dorn et al. 2008), and both the 'Exxon Valdez' oil spill and a shift in the Pacific Decadal Oscillation (PDO) were observed, the intervention effects of which are assessed below.

\section{MATERIALS AND METHODS}

Data. Larval pollock abundance and hatchdate data were obtained from annual surveys of Shelikof Strait in late May to early June from 1981 to 2001 (data from 1982 and 1984 were not used because larval surveys in these years were made earlier in May and were more limited in extent than in the other years). Generally, sampling began near Unimak Pass and continued along the southern side of the Alaska Peninsula to northeast of Kodiak Island; we used a subset of the stations that were consistently sampled (Fig. 1). Sampling was done with bongo frames equipped with a $500 \mu \mathrm{m}$ mesh plankton netting from $100 \mathrm{~m}$ to the surface. Comparisons of pollock larvae catches using larger nets in late May and day/night catch ratios indicate that there is no gear avoidance by larger larvae at that time (Shima \& Bailey 1994). Otoliths were dissected out and daily increments counted under a microscope following protocols described by Yoklavich \& Bailey (1990). Briefly, freshly caught larvae were preserved in $95 \%$ ethanol. Otoliths were dissected out and mounted in nail polish. The sagittal otoliths were read using transmitted light at $1000 \times$ magnification. The daily deposition of growth increments for larval pollock has been demonstrated (Nishimura \& Yamada 1984, Bailey \& Stehr 1988). Age frequencies were determined and used to estimate population hatchdate distribution (hatchdate = capture date - age) (Hinckley et al. 1993). Age frequencies from each sample were standardized to the mean survey date (Bailey et al. 1996). The log abundances of pollock larvae were plotted against their hatchdates year-by-year, with the raw data denoted by open circles (see Fig. 2). Otoliths were not available for 1981 and so the age frequency was estimated from the late May length frequency in 1981 and the average growth

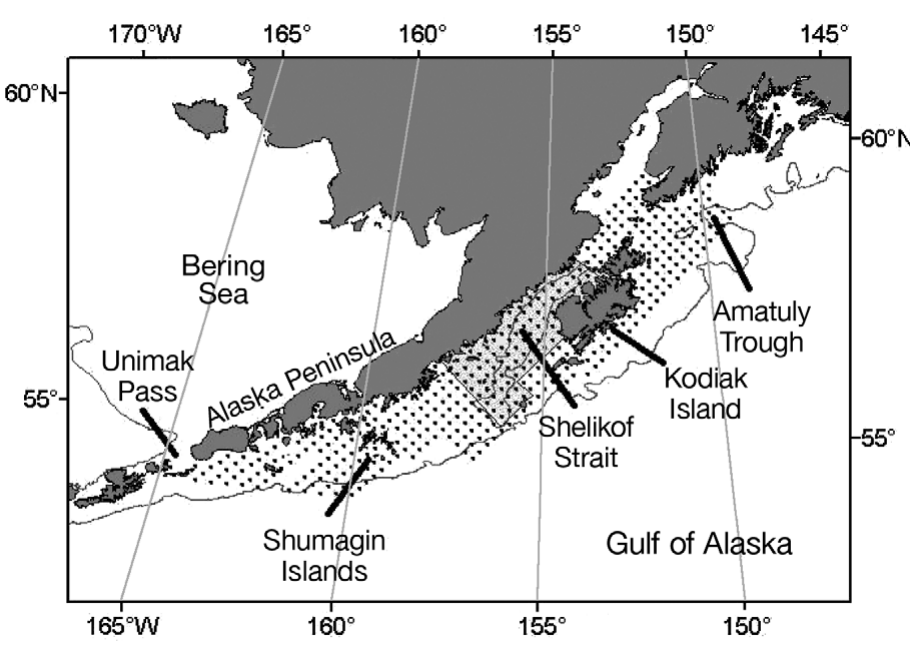

Fig. 1. Sampling region. Shaded: fish sampling for hatchdate analysis 
rate from the other years. Several covariates were derived from 4 environmental variables, namely, drift out of GOA (Transport), (anomalous) sea surface temperature (SST), (anomalous) surface wind speed in Shelikof Strait (WindS), and the PDO; data were obtained from the Pacific Marine Environmental Laboratory (A. Macklin \& M. Spillane unpubl. data). For untangling the environmental effects on spawning/ hatching and larval survival, we generally computed 2 auxiliary variables from each of Transport, SST and WindS by averaging each over (1) $30 \mathrm{~d}$ before the hatchdate, and (2) the period between the hatchdate and the catch date (see Supplement at www.int-res. com/articles/suppl/m412p001_supp.pdf). For assessing how large-scale climatic patterns may alter the shape and/or height of the hatchdate frequency distribution, we also computed the mean anomalous PDO levels from January to March, the 3 mo period before spawning. (We have also computed PDO as averages over shorter or longer periods, but mean PDO from January to March was selected according to the model selection criterion detailed below.) The biological factors consisted of pollock spawning biomass and age structure.

The model. The baseline hatchdate frequency distribution (as determined by the underlying spawning distribution) may be specified as proportional to some discrete probability distribution denoted by $\exp [s(t)]$, which equals the probability that a larva hatches on Day $t$. As the functional form of $s(t)$ is unknown, it is specified as a nonparametric, smooth function in $t$. Assuming a log-logistic distribution (Bennett 1983) for the lifespan distribution of larvae, the baseline probability that a larva survives $k$ or more days equals $1 /\left[1+(\lambda k)^{\gamma}\right]$, where $\gamma>0$ is the shape parameter of the distribution and the reciprocal of $\lambda>0$ is the scale parameter, specifically the median life expectancy. An important property of the log-logistic distribution is its ability to capture non-monotone hazard rate. Indeed, for the $\log$-logistic distribution with $\gamma>1$, its hazard function, the value of which at $k \geq 0$ equals the probability of instantaneous death given survival for at least $k$ days, is unimodal. On the other hand, for $\gamma \leq 1$, the hazard function is monotonically decreasing. Then let $\exp \left(\beta_{0}\right)$ be the catch probability, which is assumed constant over the study period. These baseline probabilities describe the situation in a typical year in which the probability that a larva hatched on Day $t$ survived for more than $k$ days and was caught on Day $t+k$ equals $\exp [s(t)] \exp \left(\beta_{0}\right) /\left[1+(\lambda k)^{\gamma}\right]$. However, both the hatching and survival processes are influenced by environmental conditions, so modifications are needed.

(1) Young and older spawners may have different egg productivity and spawning time distributions, resulting in a mixture of hatchdate distributions. Let $\alpha_{y, a}$ be the proportion of Group $\alpha$ in Year $y$ (only 2 groups were considered, with Group 1 comprising of fish $8 \mathrm{yr}$ and older and Group 2 consisting of young spawners 4 to 7 yr old). We assumed that, on the log scale, the baseline probability that a larva is hatched on Day $t$ of Year $y$ is (approximately) proportional to: $\exp \left[\alpha_{y, 1} s_{1}(t)+\alpha_{y, 2} s_{2}(t)\right]$, where the hatchdate distribution of eggs from Group-a equals $s_{a}(t), a=1,2$, on the log scale, up to some additive constant (see Supplement).

(2) Environmental effects on spawning and hatching can alter the height uniformly and/or the shape of the hatchdate frequency distribution on the log scale so that the frequency of hatching on Day $t$ of Year $y$ is proportional to:

$\exp \left[\alpha_{y, 1} s_{1}(t)+\alpha_{y, 2} s_{2}(t)+\sum_{j=1}^{p_{1}} B_{y, j} s_{B j}(t)+\sum_{j=p_{1}+1}^{p} s\left(B_{t, y, j}\right)\right]$

where $B_{y, 1}, \ldots, B_{y, p_{1}}$ are $p_{1}$ yearly environmental factors that alter the shape (and height) of the hatching distribution through $B_{Y, j} S_{B j}(t), j=1, \ldots, p_{1}$, and $B_{t, y_{1}, p_{1}+1}, \ldots$, $B_{t, y, p}$ are $\left(p-p_{1}\right)$ environmental covariates over a period of $30 \mathrm{~d}$ prior to Day $t$ of Year $y$ that alter the height of the hatching distribution. The function $s_{B j}(t)$ can be interpreted as the (additive) change in the (log) hatchdate frequency distribution per unit increase in the covariate $B_{j}$. The functions $s$, with distinct arguments, are generally distinct smooth functions. As the functional forms of the environmental effects are generally unknown, they are specified as smooth functions. Similarly, we nonparametrically model the environmental effects on survival multiplicatively so that the (conditional) probability that a larva, hatched on Day $t$ of Year $y$ lived for $k$ or more days equals

$$
\exp \left[\sum_{l=1}^{q} s\left(A_{t, k, Y, l}\right)\right] /\left[1+(\lambda k)^{\gamma}\right]
$$

where $A_{t, k, y, l}, \ldots, A_{t, k, y, q}$ are $q$ environmental variables measured over the period between Day $t$ when the larva was hatched and Day $t+k$ of Year $y$ when it was caught.

For the log-logistic distribution, the baseline hazard rate (the instantaneous probability of a larva dying at Time $s$ given its survival just before $s$ ) at Age $k$ days of the above log-logistic distribution equals $\lambda \gamma(\lambda k)^{\gamma-1} /$ $\left[1+(\lambda k)^{\gamma}\right]$. Note that the preceding expression is equivalent to $\gamma k^{\gamma-1} /\left(\lambda^{-\gamma}+k^{\gamma}\right)$ showing that for fixed $\gamma>0$, the hazard function is an increasing function of $\lambda$ This fact is useful for interpreting the proposed intervention models.

The intervention from the climate regime shift and/or the oil spill in 1989 may alter the (daily) hazard rate. The effects of an intervention in 1989 on the survival of larvae can be modeled by keeping the shape parameter of the log-logistic distribution fixed but changing the parameter $\lambda$, which in the survival func- 
tion for 1989 may differ from the baseline by a multiplicative constant equal to $\left(1+\psi_{1989}\right)$. The ratio of the hazard rates in 1989 relative to the baseline is equal to $\left.\left(1+\psi_{1989}\right)^{\gamma}\left[1+(\lambda k)^{\gamma}\right] /\left\{1+\left(1+\psi_{1989}\right) \lambda k\right]^{\gamma}\right\}$, which is an increasing function of the intervention parameter $\psi_{1989}$. Hence, for $-1<\psi_{1989}<0$, the hazard rate function in 1989 is lower than the baseline, whereas $\psi_{1989}>0$ corresponds to an elevated hazard rate function in 1989. For $\psi_{1989}=0$, there are no intervention effects. We postulate that the intervention effects after 1989 may diminish geometrically, so that the $\lambda$ parameter in the $m$ th year after 1989 is modified by the multiplicative coefficient $\left(1+\phi^{m} \psi_{1989}\right)$. Note that for $0<\phi<1$ the intervention effects decay geometrically, whereas the case $\phi=0$ implies no after-effects and the case $\phi=$ 1 signifies permanent, constant intervention effects. Therefore, we modified the $\lambda$ parameter by the multiplicative constant $\left(1+\phi^{Y-1989} \psi_{1989} 1_{(y \geq 1989)}\right)$, in Year $y$ with $y \geq 1989$, where the dummy variable $1_{(y \geq 1989)}$ equals 1 for years in 1989 and after, but otherwise equals zero. The term $\phi^{y-1989} \psi_{1989} 1_{(y \geq 1989)}$ then models the situation such that the 1989 intervention affected the larval hazard rate in 1989 and afterwards, but its effects might decline geometrically after 1989.

The value of the parameter $\phi$ may shed valuable insights on the intervention effects on larval survival. If it is $<1$ in magnitude, then the intervention effects vanish geometrically fast, although when $\phi \approx 1$, the geometric decay may resemble linear decay. A concrete way to quantify the rate of decay is to consider half-life, which is defined to be the time needed for the intervention effects to be reduced in magnitude by half. For the case that $0<\phi<1$ the half-life for the post1989 intervention effects equals $\log (0.5) / \log (\phi)$. In the model estimation, no constraint was imposed on $\phi$. Altogether, based on the preceding considerations, we formulated the following model:

$$
\begin{aligned}
l_{t, k, Y}= & n_{y}+\alpha_{y, 1} s_{1}(t)+\alpha_{y, 2} s_{2}(t)+\sum_{j=1}^{p_{1}} B_{y, j} s_{B j}(t)+\sum_{j=p_{1}+1}^{p} s\left(B_{t, y, j}\right) \\
& -\log \left\{1+\left[\left(1+\phi^{y-1989} \psi_{1989} 1_{(y \geq 1989)}\right) \lambda k\right]^{\gamma}\right\} \\
& +\sum_{l=1}^{q} s\left(A_{t, k, y, l}\right)+\varepsilon_{t, k, Y}
\end{aligned}
$$

where $l_{t, k, Y}$ is the log abundance of the captured larval pollock that were hatched on Day $t$ of Year $y$, and caught on Day $t+k$, and $n_{y}$ is the log spawning biomass in Year $y_{i} 1_{(\cdot)}$ is the dummy variable for the expression within the parentheses, i.e. it equals 1 if the expression holds and 0 otherwise; $\varepsilon_{t, k, y}$ are uncorrelated, normally distributed errors of zero mean and identical variance. Note that the catching probability parameter $\beta_{0}$ and the age-specific productivity factors are absorbed into the hatchdate frequency functions $s_{\mathrm{a}}$. All other smooth functions without subscripts are centered to have zero mean over the data, because without these centering constraints, the model is not identifiable; we can add a constant to one such smooth function and subtract the same constant from another such smooth function without altering the function fit.

Model fitting and selection. The model defined by Eq. (3) and its variants are estimated by the method of penalized least squares, which estimates the unknown functions and parameters by minimizing the penalized residual sum of squares; the latter objective function is the sum of the residual sum of squares and the penalty terms on the roughness of each unknown smooth function. The roughness penalty of a smooth function is proportional to the integrated squared second derivative of the function. The proportional coefficients, also known as the smoothing parameters, can be determined by generalized cross validation (GCV) (T. Zhang \& K. S. Chan unpubl.). For fixed smoothing parameters, optimization of the penalized residual sum of squares can be achieved iteratively by alternately updating the smooth function estimates, which are natural cubic splines, and the survival parameters, each of the sub-steps being straightforward. For selecting among the various models, we employed a recently developed model selection criterion (T. Zhang \& K. S. Chan unpubl.), which is similar to the Bayesian information criterion (BIC) and is an approximation of the log marginal likelihood of a model, via the Laplace approximation (Tierney et al. 1989). (Here, the penalty terms together induce an improper normal prior, conditional on the estimated smoothing parameters.) The marginal likelihood of a model is proportional to the posterior probability of the model, assuming constant prior probabilities for the models under consideration. Models with higher log marginal likelihoods are hence preferred. We used the log marginal likelihood to determine (1) which covariates will be included as environmental factors and (2) the significance of the 1989 intervention effects on larval survival. The summarized fitting results for a number of models with 3 different specifications of intervention effects for 1989 and 2 sets of covariates are presented in Table S1 in the supplement at www.int-res.com/articles/suppl/ m412p001_supp.pdf.

\section{RESULTS}

The model defined by Eq. (3) and its variants are instances of the partly parametric nonlinear regression model which differs from the generalized additive model (GAM) (Wood 2006) by having a parametric nonlinear component (the term on the second line in Eq. 3). They can be fitted by the method of penalized 
maximum likelihood (Table 1) (T. Zhang \& K. S. Chan unpubl.). Based on marginal likelihood (Table S1 in the Supplement), the following model is most consistent with the data:

$$
\begin{aligned}
l_{t, k, y}= & n_{y}+\alpha_{y, 1} s_{1}(t)+\alpha_{y, 2} s_{2}(t)+P D O B_{Y} S_{P D O B}(t)+s\left(S S T B_{t, y}\right) \\
& +s\left(\text { WindS }_{t, y}\right)-\log \left\{1+\left[\left(1+\phi^{y-1989} \psi_{1989} 1_{(y \geq 1989)}\right) \lambda k\right]^{\gamma}\right\} \\
& +s\left(\operatorname{Trans}_{t, k, y}\right)+s\left(S S T A_{t, k, y}\right)+s\left(\text { WindSA }_{t, k, y}\right)+\varepsilon_{t, k, y}
\end{aligned}
$$

where $\psi_{1989}$ quantifies the intervention effects in 1989 , and $0 \leq \phi \leq 1$ describes the strength of memory of the intervention; $P D O B_{y}$ equals the mean anomalous PDO level from January to March of Year $y_{i} S S T B$ and SSTA are the $30 \mathrm{~d}$ average SST anomalies before the hatchdate and the average SST anomalies from the hatchdate to the catch date, respectively. Generally, the last letter B (A) in a variable name stands for before (after) hatching. See Table 2 for a key to the model parameters in Eq. (4).

For the fit of the model defined by Eq. (4) using the full dataset, there are 4 outliers with standardized residuals smaller than -4: Day 101 in 1999, Day 136 in 1991, and Days 87 and 88 in 1981. The log abundance of pollock larvae on these 4 days is marked as ' $X$ ' in Fig. 2. Day 101 in 1999 was the earliest hatching date, and there is no pollock abundance information for the following $11 \mathrm{~d}$. Moreover, the larval abundance estimate on Day 101 in 1999 is very low, suggesting that it was based on relatively few age samples. Day 136 was the last hatching date in 1991 and the larval abundance estimate on this day is much lower than the other late-hatching larval abundance data in the same year. In 1981, larval abundances on Days 87 and 88
Table 1. Parameter estimates of the model defined by Eq. (4). The estimation was made using the method of penalized maximum likelihood. See Table 2 for a key to the 4 parameters listed in the table

\begin{tabular}{|lclcr|}
\hline Parameter & Estimate & SE & $z$ & $\mathrm{p}(>\mathrm{z})$ \\
\hline$\lambda$ & 0.0801 & 0.019 & 4.21 & $<0.001$ \\
$\gamma$ & 2.18 & 0.35 & 6.21 & $<0.001$ \\
$\psi_{1989}$ & 1.89 & 0.68 & 2.78 & 0.005 \\
$\phi$ & 0.466 & 0.061 & 7.70 & $<0.001$ \\
\hline
\end{tabular}

were exactly the same as on Day 74, which is the lowest larval abundance in that year. Model diagnostics suggest that the fitted model defined by Eq. (4) provides a good fit to the data after removing the 4 outliers (see Supplement).

There were significant additive effects of the environmental factors on the spawning, hatching and survival of pollock larvae (Fig. 3). The baseline hatching distribution (on the log scale) of eggs from the older spawners (Fig. 3a) differed from that of the younger spawners (Fig. 3b). The mean (log) hatching abundance of older spawners (20.4) was significantly higher than that of younger spawners (19.1) ( $p<0.001)$. The hatchdate distribution for the older group had a peak around Day 82 and a secondary peak near Day 112, suggesting that spawning from the older group peaks around Days 68 and 98 (based on a 14 d egg incubation). The data forming the first peak are sparse, and an alternative explanation is that these older larvae were immigrants from an unknown upstream spawning location. On the other hand, the hatchdate distribution for the younger group was relatively flat, sug-

\begin{tabular}{|c|c|c|}
\hline Model parameters & Description & Biological assumptions \\
\hline$\lambda$ & $\begin{array}{l}\text { The reciprocal of } \lambda \text { is the scale parameter of the log- } \\
\text { logistic survival function and the median life } \\
\text { expectancy of pollock larvae }\end{array}$ & $\begin{array}{l}\text { Lifespan distribution of pollock larvae has a } \\
\text { monotone or unimodal hazard rate function }\end{array}$ \\
\hline$\gamma$ & Shape parameter of the log-logistic survival & \\
\hline$\psi_{1989}$ & Intervention effects in 1989 & $\begin{array}{l}\text { Intervention affected the hazard rate multi- } \\
\text { plicatively }\end{array}$ \\
\hline$\phi$ & Annual decay rate of the intervention effects after 1989 & \\
\hline$s_{1}(t)$ & $\begin{array}{l}\text { (Log) hatchdate frequency distribution of eggs from old } \\
\text { spawners }\end{array}$ & $\begin{array}{l}\text { All smooth effects except the PDO effects are } \\
\text { smooth additive effects on the logarithmic scale }\end{array}$ \\
\hline$s_{2}(t)$ & $\begin{array}{l}\text { (Log) hatchdate frequency distribution of eggs from } \\
\text { young spawners }\end{array}$ & \\
\hline$\alpha_{y, 1}$ & Annual proportion of older spawners & \\
\hline$\alpha_{y, 2}$ & Annual proportion of younger spawners & \\
\hline$S_{\mathrm{PDOB}}(t)$ & $\begin{array}{l}\text { Hatchdate frequency distribution per unit change in } \\
\text { PDO }\end{array}$ & $\begin{array}{l}\text { PDO affected both the shape and the level of } \\
\text { the hatchdate frequency distribution }\end{array}$ \\
\hline$s\left(\mathrm{SSTB}_{t, y}\right)$ & Sea surface temperature effects on hatching & \\
\hline$s\left(\right.$ WindSB $\left._{t, y}\right)$ & Wind speed effects on hatching & \\
\hline$s\left(\right.$ Trans $\left.A_{t, k, y}\right)$ & Transport effects on larval survival & \\
\hline$s\left(\mathrm{SSTA}_{t, k, y}\right)$ & Sea surface temperature effects on larval survival & \\
\hline$s\left(\right.$ WindSA $\left._{t, k, Y}\right)$ & Wind speed effects on larval survival & \\
\hline
\end{tabular}
gesting a more variable spawning time distribution.

Table 2. Model parameters, their descriptions and biological assumptions. PDO: Pacific Decadal Oscillation 


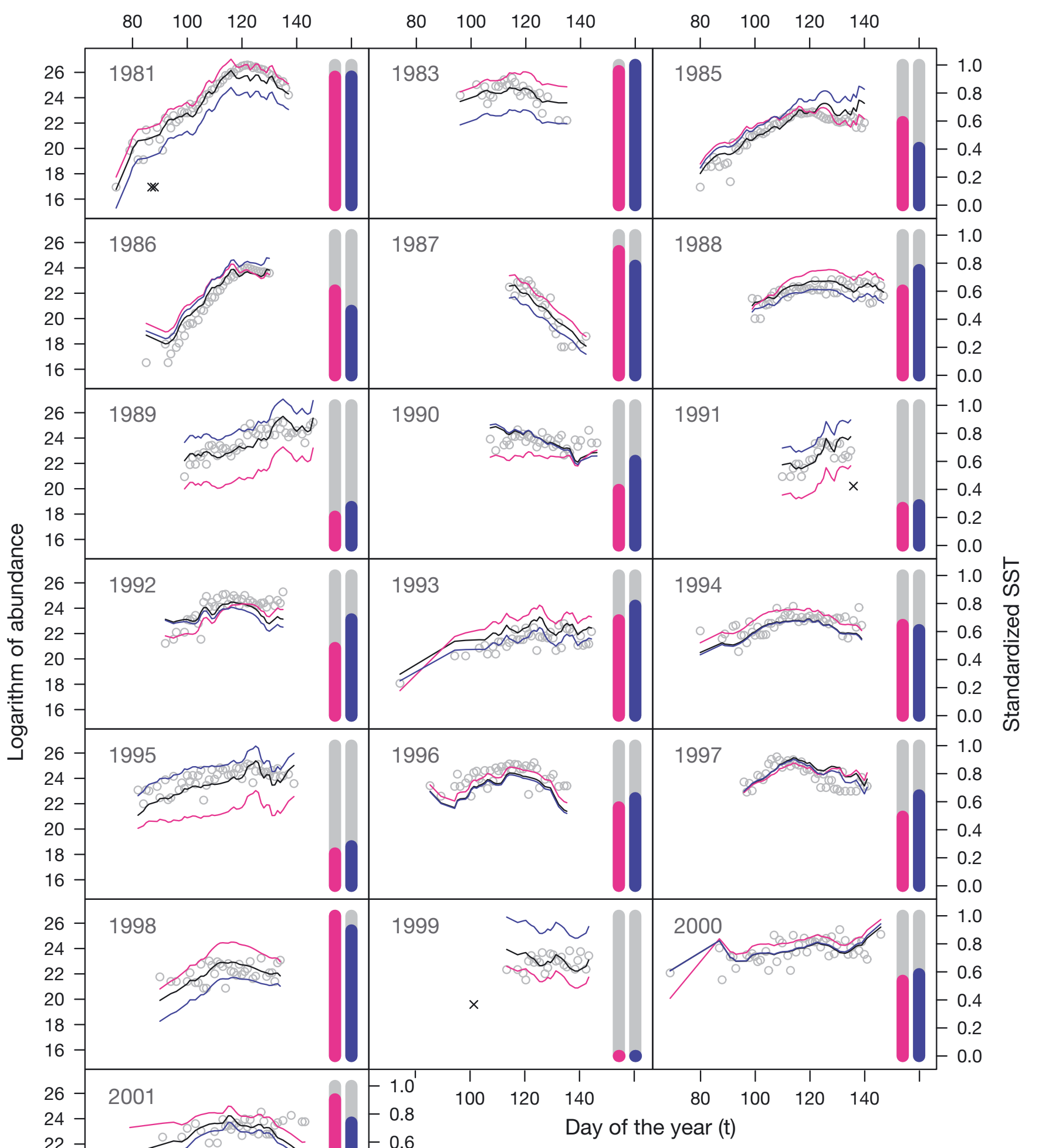

Fig. 2. Theragra chalcogramma. Logarithm of larval pollock abundance (O) over hatchdate, with fitted log abundance curves derived from the model defined by Eq. (4) (black curves). $\times$ : outliers removed from analysis. Red curves: fitted values with SSTB effects omitted (SST effects on spawning and hatching); blue curves: fitted values with SSTA effects omitted (SST effects on larval survival). Red bar represents average annual SSTB; blue bar represents yearly average SSTA; SST scaled to a range from 0 to 1 

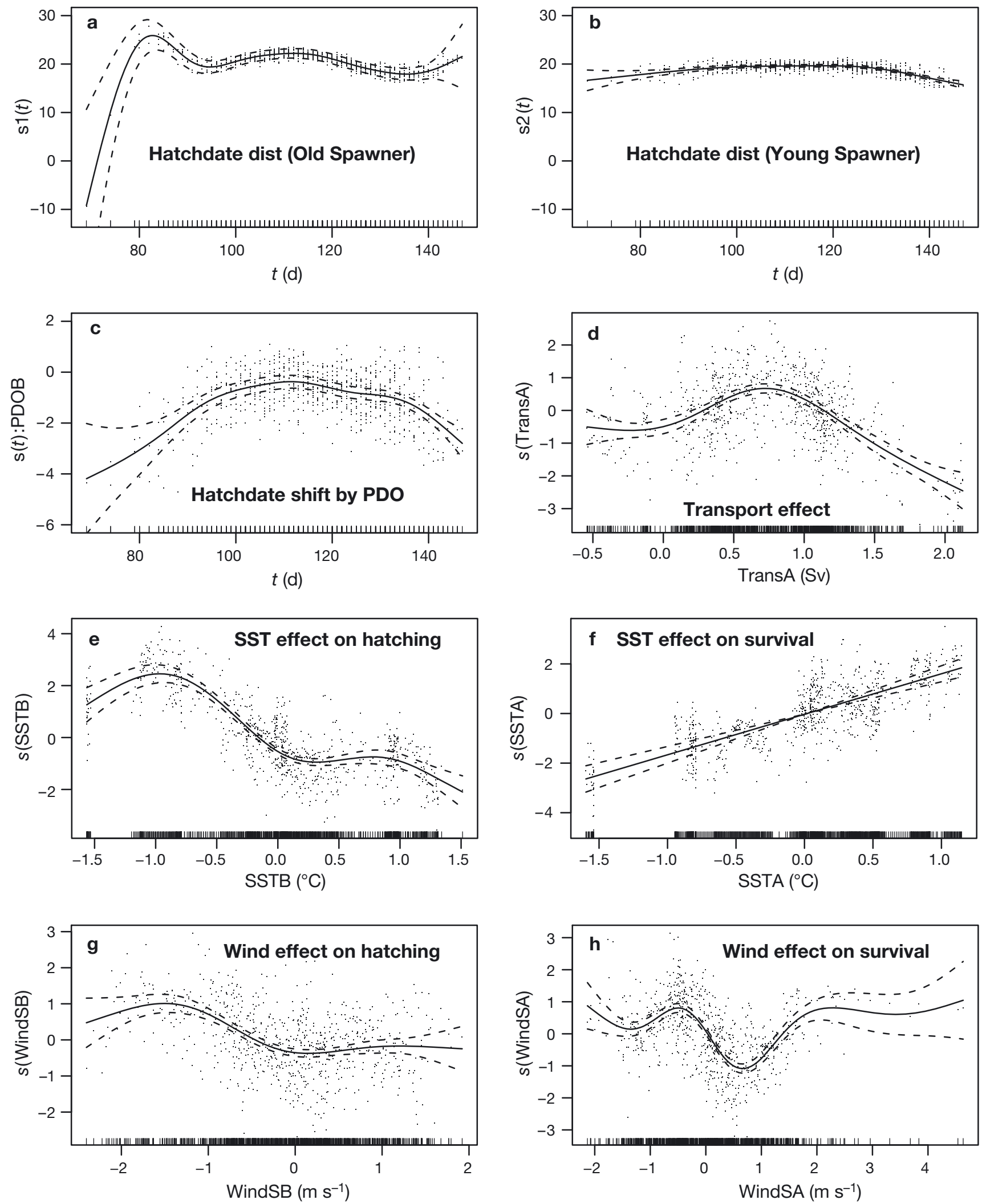

Fig. 3. Theragra chalcogramma. Smooth function estimates of the covariate effects on hatching and survival of larval pollock; dist: distribution; PDO: Pacific Decadal Oscillation; SST: sea surface temperature. Solid lines: estimated additive covariate effects. Dashed lines: $95 \%$ confidence bands. Dots: partial residuals. See Table 2 for further abbreviations 
The hatchdate frequency distribution changed with the PDO (Fig 3c); the curve is entirely below zero, so higher PDO values tended to be associated with lower spawning and hatching. The unimodality and the drop-off of the left tail of the curve in Fig. 3c indicate that higher PDO was associated with relatively more intensive spawning during the middle of the spawning period.

There is a nonlinear 'transport effect' on larval survival (Fig. 3d). The positive 'transport effect' may be explained by some beneficial effects of moderate transport related to nutrient input and enhanced prey production. However, when the transport out of GOA was strong, it flushed pollock larvae out of the area and reduced larval abundance.

Higher SSTs before hatching were associated with lower larval abundance (Fig. 3e), which may be explained as follows: during the spawning months, SST is strongly correlated with bottom temperature due to a well-mixed water column. In relatively warm temperatures, spawning occurs earlier and the turnover of eggs is faster so that larvae have a longer duration in the water before capture; therefore, they experience a higher cumulative mortality (although not necessarily a higher instantaneous mortality) prior to capture. The opposite may hold in colder environments, as eggs would have a longer development time and spawning occurs later than in an average year; therefore, larvae would have a shorter development before capture. Higher SSTs after spawning resulted in higher survival rates (Fig. 3f). Strong winds appeared to depress pol-

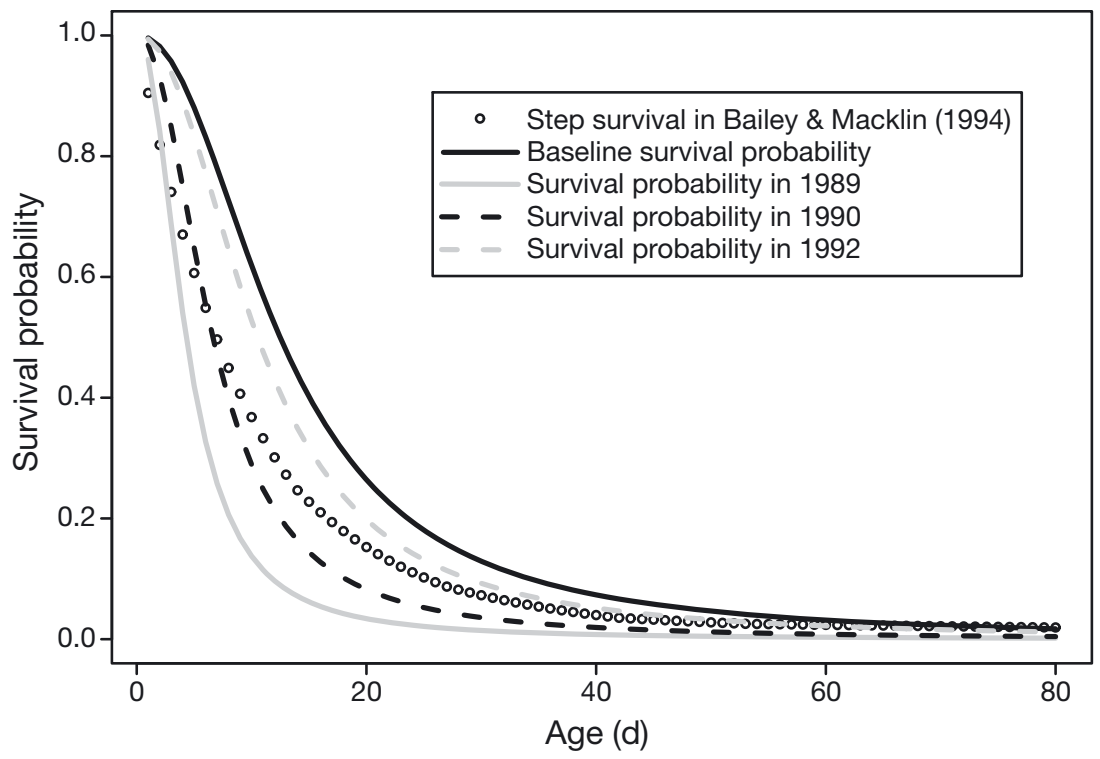

Fig. 4. Theragra chalcogramma. Estimates of the survival probability curves of larval pollock. While the 1989 intervention suppressed the survival curve in 1989 to be mostly lower than the baseline curve, the survival probability curve became quite close to the baseline after about $3 \mathrm{yr}$, due to the pollock population having a weak memory of the 1989 intervention lock spawning and reduced larval survival, based on the data intensive parts of Fig. $3 g$, h. The data on the right tail of the curve in Fig. 3h correspond mainly to the late hatching dates; the unexpected positive relationship between wind speed and survival during the late hatching period may be caused by the confounding effects of water stratification late in the season. The effect of winds on spawning is difficult to explain, but it may be related to linkages among winter storminess, currents, and temperature, and their effects on spawning location and timing.

An alternative approach for visualizing the annual SST anomaly effects on the hatching and larval survival processes is to compare the fitted values from the final model with those having the SSTB (SSTA) effects suppressed. In each panel in Fig. 2, we plot the fitted values (black lines), the fitted values with the SSTB effects omitted (SST effects on spawning and hatching; red lines) and the fitted values with the SSTA effects omitted (SST effects on larval survival; blue lines). Average SSTB and SSTA are represented by 2 thermometers, where the red bar is proportional to the average SSTB whereas the blue bar is proportional to the average SSTA. Therefore, the difference between the black line and the red line in each year represents the SST effect on hatching and spawning. For example, in 1983, the black line is lower than the red line, so that the SST in that year tended to depress pollock spawning and hatching and consequently reduced the larval abundance. Similarly, the differences between the black lines and the blue lines reflect the SST effects on larval survival.

Before 1989, warm SST tended to depress pollock spawning and hatching. However, the SST declined in 1989 and remained low through 1991 and was associated with increased pollock spawning and hatching. These climatic changes are consistent with the climate regime shift discussed by Hare \& Mantua (2000) and Ciannelli et al. (2007). Note that besides the 1989 to 1991 period, the year 1995 is also characterized by a decreased SST and significant positive SST effects on hatching; however, this is just a $1 \mathrm{yr}$ phenomenon.

The baseline probability for the larval pollock to survive $k$ or more days was estimated to equal $1 /\left[1+(0.08 k)^{2.18}\right]$ (Fig. 4). The 1989 intervention depressed the survival probability function in 1989 to $1 /\left[1+(0.23 k)^{2.18}\right]$; estimates of $\psi_{1989}$ and $\phi$ are significantly different from 0 (2sided $\mathrm{p}<0.05)$, suggesting significant reductions in the survival rate due to the 
intervention in 1989. Based on the estimated $\phi(0.466)$, the 1989 intervention left a weak memory in the pollock population, having a half-life of about 11 mo (Box \& Tiao 1975, Cryer \& Chan 2008). By 1990, the change in hazard rate was about $46.6 \%$ of the change in 1989 , while by 1992 , the change was only $10 \%$ of the change in 1989 (see Fig. 4). Such a fast rate of decay indicates a quick recovery from the 1989 intervention.

\section{DISCUSSION}

We have developed a novel statistical framework for extracting the rich information from a dataset of otolith time series, which is useful for revealing the dynamics in fish larvae. Fisheries managers generally lack solid information about the time when spawning habitat is utilized by pollock, the interannual variability in the timing of spawning and the effects of environmental conditions. Assessment surveys of adult spawners start well before spawning commences and generally end before the peak of spawning. These give a snapshot of the brief interval just as spawning starts. In particular, we do not know how the effect of fishing on the age structure of the population impacts the timing of spawning or the duration of habitat utilization. Otolithbased time markers left in the water column (i.e. in the larvae themselves) by spawners provide a continuous documentation of spawning and environmental effects, analogous to a recording as opposed to a snapshot. What had been missing was an appropriate methodology to interpret this information.

We found that environmental factors had a significant influence on the timing of spawning and on survival of pollock larvae in the GOA. In summary, cold temperatures prior to spawning tended to increase later larval abundance, possibly because of delayed spawning and increased duration of egg development, resulting in a shorter period between hatching and capture and less cumulative mortality. In warm temperatures, spawning is earlier, turnover of eggs is faster, and cumulative mortality experienced is higher by the time of the survey. Sea temperatures also influence the spatial distribution of spawning, and higher temperatures are associated with increased spawning outside our survey grid (Bacheler et al. 2009). On the other hand, high SSTs after spawning enhance larval survival. Moderate transport conditions benefited larval pollock, while strong drift tended to reduce the larval stock. The results demonstrating that pollock larvae had higher survival in a warm environment, while strong winds decreased larval survival, are consistent with previous studies showing that temperature and winds influence larval pollock mortality rates (Bailey et al. 1996) and recruitment (Ciannelli et al.
2004). Instantaneous mortality rates of larvae are decreased in warmer water conditions (Bailey 2000). Strong winds disrupt the survival of larvae due to either the effects of turbulence on feeding rates (Porter et al. 2005) or transport of larvae into offshore regions where feeding conditions may be poor (Bailey \& Macklin 1994).

Wintertime PDO conditions affected both the shape of the hatchdate distribution and the level of abundance. The unimodal curve found here depicts the additive change in the hatchdate frequency curve per unit change in the PDO. A higher PDO implies that the hatchdate frequency curve attains a lower level and is more peaked. Therefore, spawning may be more intense. Since high PDO is associated with warmer temperatures, the effect on the level of the hatchdate distribution is consistent with the explanation of the temperature effect. Alternatively, the lowered level of the hatchdate distribution with high PDO and temperature may result from a shift in the spawning distribution (Bacheler et al. 2009).

The fitted model depicts the spawning time distribution as dome-shaped, with a higher peak for the older spawner group than the younger group. Therefore, factors that influence the age structure of the population, such as harvesting of the older age classes, may increase variability in the timing of spawning. There is also evidence from histological examination of ovaries of GOA walleye pollock (Merati 1993) and from the examination of gonads of walleye pollock caught in the Okhotsk Sea (Kotenev et al. 1998) that the spawning time of smaller and larger individuals differs.

Natural (regime shift) and/or human interventions (e.g. the 'Exxon Valdez' oil spill) reduced the survival rate of pollock larvae in 1989. The effect of an environmental regime shift in 1989 (Hare \& Mantua 2000) is unexplored, but there may have been a shift in spawning location (Ciannelli et al. 2007). In the spring of 1989, the 'Exxon Valdez' oil spill flowed through Shelikof Strait during the period when larval pollock were most abundant there. The spill occurred on March 24 in Prince William Sound and by May 2 reached the eastern shore of the Alaska Peninsula (Royer et al. 1990, Rice et al. 2006) and the walleye pollock nursery in Shelikof Strait. The spill severely impacted fish, causing 13 billion herring mortalities in the northern GOA (Rice et al. 2006). Plankton nets in early May surveys of Shelikof Strait were fouled with oil. To date, the impact of the oil spill on the spawning habitat of walleye pollock has not been assessed. As the spill and regime shift events happened concurrently, their effects are likely intertwined. We speculate that the residual effects after 1989 may have been related to effects on adult spawning behavior and spawning location. However, the intervention effects on larval 
abundance decayed at a geometric rate after 1989, so the system has a rather weak memory of the intervention.

We have presented a novel approach to examine the complex interactions of environmental and human effects and interventions on the recruitment process of marine fishes. The shape, height and modality of time series of larval hatchdate distributions are determined by the balance between the intensity and distribution of spawning, hatching rate, and survival. There are other applications for which this approach should prove useful.

Acknowledgements. We thank A. Dougherty for otolith reading and summarizing some environmental data. This is FOCI contribution 0733-ROA. This research was partly funded by NSF (CMG-0620789) and by Essential Fish Habitat funds provided by the Alaska Regional Office and Alaska Fisheries Science Center. This article contains supporting information online at www.int-res.com/articles/suppl/m412p001_supp.pdf.

\section{LITERATURE CITED}

Abrams MD, van de Gevel S, Dodson RC, Copenheaver CA (2000) The dendroecology and climatic impacts for oldgrowth white pine and hemlock on the extreme slopes of the Berkshire Hills, Massachusetts. Can J Bot 78:851-861

Bacheler NM, Bailey KM, Ciannelli L, Bartolino V, Chan KS (2009) Density-dependent, landscape, and climate effects on spawning distribution of walleye pollock Theragra chalcogramma. Mar Ecol Prog Ser 391:1-12

Bailey KM (2000) Shifting control of recruitment of walleye pollock Theragra chalcogramma after a major climactic ecosystem change. Mar Ecol Prog Ser 198:215-224

Bailey KM, Macklin A (1994) Analysis of patterns in larval walleye pollock Theragra chalcogramma survival and wind mixing events in Shelikof Strait, Gulf of Alaska. Mar Ecol Prog Ser 113:1-12

Bailey KM, Stehr CL (1988) The effects of feeding periodicity and ration on the rate of increment formation in otoliths of larval walleye pollock Theragra chalcogramma (Pallas). J Exp Mar Biol Ecol 122:147-161

Bailey KM, Picquelle SJ, Spring SM (1996) Mortality of larval walleye pollock Theragra chalcogramma in the western Gulf of Alaska, 1988-1991. Fish Oceanogr 5(Suppl.1): $124-136$

Bennett S (1983) Log-logistic regression models for survival data. Appl Stat 32:165-171

Box GEP, Tiao GC (1975) Intervention analysis with applications to economic and environmental problems. J Am Stat Assoc 70:70-79

Chan KS, Stenseth NC, Lekve K, Gjøsæter J (2003) Modeling pulse disturbance impact on cod population dynamics: the 1988 algal bloom of Skagerrak, Norway. Ecol Monogr 73: 151-171

Ciannelli L, Chan KS, Bailey KM, Stenseth NC (2004) Nonadditive effects of the environment on the survival of a large marine fish population. Ecology 85:3418-3427

Ciannelli L, Bailey KM, Chan KS, Belgrano A, Stenseth NC (2005) Climate change causing phase transitions of walleye pollock (Theragra chalcogramma) recruitment dynamics. Proc R Soc Lond B Biol Sci 272:1735-1743

Ciannelli L, Bailey KM, Chan KS, Stenseth NC (2007) Pheno-

Editorial responsibility: Hans Heinrich Janssen,

Oldendorf/Luhe, Germany logical and geographical patterns of walleye pollock spawning in the western Gulf of Alaska. Can J Fish Aquat Sci 64:713-722

Cryer JD, Chan KS (2008) Time series analysis with applications in R. Springer Verlag, New York

Cushing DH (1990) Plankton production and year-class strength in fish populations: an update of the match/mismatch hypothesis. Adv Mar Biol 26:249-293

Dorn M, Aydin K, Barbeaux S, Guttormsen M, Megrey B, Spalinger K, Wilkins M (2008) Stock assessment and fishery evaluation report: Gulf of Alaska walleye pollock. North Pacific Fishery Management Council 605 W 4th Avenue, Suite 306 Anchorage, AK 99501, p 53-168. Available at: www.afsc.noaa.gov/REFM/docs/2007/GOApollock. pdf

Fromentin JM, Myers RA, Bjornstad ON, Stenseth NC, Gjosaeter J, Christie H (2001) Effects of density-dependent and stochastic processes on the regulation of cod populations. Ecology 82:567-579

- Hare SR, Mantua NJ (2000) Empirical evidence for North Pacific regime shifts in 1977 and 1989. Prog Oceanogr 47: 103-145

Hinckley S, Bailey KM, Picquelle S, Yoklavich M, Stabeno P (1993) Age-specific mortality and transport of larval walleye pollock (Theragra chalcogramma) in the western Gulf of Alaska. Mar Ecol Prog Ser 98:17-29

Houde ED (2008) Emerging from Hjort's shadow. J Northwest Atl Fish Sci 41:53-70

Hsieh CH, Kim HJ, Watson W, Di Lorenzo E, Sugihara G (2009) Climate-driven changes in abundance and distribution of larvae of oceanic fishes in the southern California region. Glob Change Biol 15:2137-2152

Kotenev BN, Kuznetsov VV, Kuznetsova EN (1998) The stock of the eastern Okhotsk walleye pollock Theragra chalcogramma and its distribution in spawning period. J Ichthyol 38:747-757

Merati N (1993) Spawning dynamics of walleye pollock Theragra chalcogramma in the Shelikof Strait, Gulf of Alaska. M.S. Thesis, University of Washington, Seattle

Nishimura A, Yamada J (1984) Age and growth of larval and juvenile walleye pollock, Theragra chalcogramma (Pallas), as determined by otolith daily growth increments. J Exp Mar Biol Ecol 82:191-205

Porter SM, Ciannelli L, Hillgruber N, Bailey KM, Chan KS, Canino MF, Haldorson LJ (2005) Analysis of factors influencing larval walleye pollock Theragra chalcogramma feeding in Alaskan waters. Mar Ecol Prog Ser 302:207-217

Rice SD, Short JW, Carls MG, Moles A, Spies RB (2006) The Exxon Valdez oil spill. In: Spies RB (ed) Long-term ecological change in the northern Gulf of Alaska. Elsevier, Oxford, p 419-520

Royer TC, Vermersch JA, Weingartner TJ, Niebauer HJ, Muench RD (1990) Ocean circulation influencing the Exxon Valdez oil spill. Oceanogr Nov 1990:3-10

Shima M, Bailey KM (1994) Comparative analysis of ichthyoplankton sampling gear for walleye pollock (Theragra chalcogramma). Fish Oceanogr 3:50-59

Stabeno PJ, Bond NA, Herman AJ, Mordy CW, Overland JE (2004) Meteorology and oceanography of the northern Gulf of Alaska. Cont Shelf Res 24:859-897

Tierney L, Kass RE, Kadane JB (1989) Fully exponential Laplace's approximations to expectations and variances of non-positive functions. J Am Stat Assoc 84:710-716

Wood S (2006) An introduction to generalized additive models with R. Chapman \& Hall, Boca Raton, FL

Yoklavich MM, Bailey KM (1990) Hatching period, growth and survival of larval walleye pollock as determined from otolith analysis. Mar Ecol Prog Ser 64:13-23

Submitted: February 19, 2010; Accepted: June 8, 2010

Proofs received from author(s): July 17, 2010 